\title{
Correction to: The intertidal mudflats of Barr Al Hikman, Sultanate of Oman, as feeding, reproduction and nursery grounds for brachyuran crabs
}

\author{
Roeland A. Bom (D) Jan A. van Gils - Karen Molenaar • Andy Y. Kwarteng • \\ Reginald Victor $\cdot$ Eelke O. Folmer
}

Accepted: 2 December 2020/Published online: 22 December 2020

(C) Springer Nature Switzerland AG 2020

Correction to: Hydrobiologia (2020) 847:4295-4309

https://doi.org/10.1007/s10750-020-04418-4

In the above mentioned publication, incorrect values for $P$. segnis are shown on the right hand side of Fig. 4.

The original article can be found online at https://

doi.org/10.1007/s10750-020-04418-4.

R. A. Bom $(\varangle) \cdot$ J. A. van Gils · K. Molenaar Department of Coastal Systems, NIOZ Royal Netherlands Institute for Sea Research, P.O. Box 59,

1790 AB Den Burg, Texel, The Netherlands

e-mail: roeland.bom@nioz.nl

R. A. Bom · A. Y. Kwarteng

Remote Sensing and GIS Center, Sultan Qaboos,

University, P.O. Box 33, PC 123 Al Khod, Oman

J. A. van Gils

Conservation Ecology Group, Groningen Institute for Evolutionary Life Sciences (GELIFES), University of Groningen, PO Box 11103, 9700 CC Groningen, The Netherlands

R. Victor

Department of Biology, College of Science, P.O. Box 36,

PC 123 Al Khod, Oman
The correct version of Fig. 4 and its caption is published here.

E. O. Folmer

Ecospace, Ecological Research and Environmental Informatics, Graspieper 1, 8532 AT Lemmer, The Netherlands 


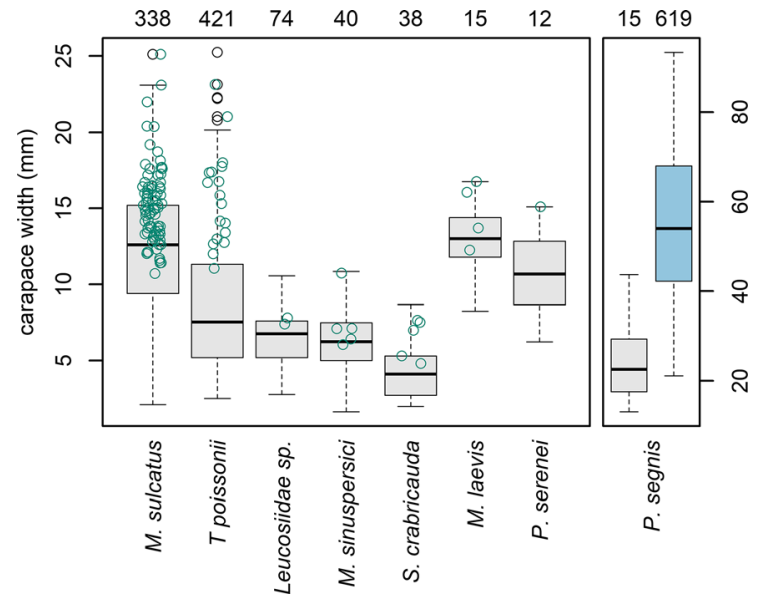

Fig. 4 Boxplots showing carapace width for the eight most abundant crab species across four winters. Thick horizontal lines show medians, top and bottom lines of the box show the 25th and 75 th percentiles respectively, whiskers show maximum and minimum values or 1.5 times the interquartile range (whichever is the smaller). For $P$. segnis grey box show crabs sampled on the grid and the blue box shows crabs collected in the intertidal water column. The green points represent the individual ovigerous female crabs (note the absence of these in P. segnis). Numbers on top show sample size
Publisher's Note Springer Nature remains neutral with regard to jurisdictional claims in published maps and institutional affiliations. 